\title{
Burnout related to occupational stress among Library and Information Professionals (LIS)
}

\author{
Rajinder Kaur Gill \\ Librarian, Arya Kanya Mahavidyalya, Shahabad Markanda, Kurukshetra
}

\begin{abstract}
:- for a long burnout related to occupational stress is recognized as a serious problem in some helping professionals such as library professions, teaching \& nursing etc. The burnout is like a process by which employees become frustrated and unproductive at the workplace due to high level of stress. This condition has many sources and may be caused by personal issues as well as work-related problems. The present paper represents the symptoms \& sources of burnout. The paper also represents the some prevention issues to remove the occupational stress as well as burnout.
\end{abstract}

Keywords: Burnout, Job, Library professionals, Occupational stress, Work-related problems.

\section{INTRODUCTION}

Studies of stress and burnout among librarians over the years have reached varied conclusions in trying to characterize or quantify the issues. Burnout - a term that is often used in a casual way to describe one's perceived stress level - is more formally appreciated as a work-life imbalance issue whose understanding has been refined by careful research for about thirty years. Job engagement is a more recently described and studied relationship with work that reflects a healthy, balanced, and emotionally present connection.

The concept 'stress' is defined in varying ways: work pressures, tight schedule, unhelpful colleagues, critical supervisors and a host of other irritating factors create the feeling of stress. Generally stress is a change which our body experienced continually depends upon the situation or demand. The stress has both, psychological or physiological effect on people depends upon the source of demand or challenge which refers to stressor. It creates both, negative or positive feeling. As a positive influence, it help a person to focus more sharply on the problem to produce solution and result in a new awareness and as a negative influence, it result in feeling of distrust, rejection, anger and depression which leads to frustration \& poor performance on the job $\&$ further prolonged stress leads to Burnout.

The term burnout refers to job-related chronic stress. In recent years, psychologists have become interested in study on phenomenon known as 'burnout'. The burnout describes the process by which employees become disillusioned, frustrated and unproductive at the workplace due to high level of stress. This condition has many sources and may be caused by personal issues as well as work-related problems. The burnout syndrome is a multi-dimensional process consisting of emotional exhaustion, depersonalization and reduced person achievement. So, Burnout is a prolonged response to chronic emotional and interpersonal stressors on the job, and is defined by the three dimensions of exhaustion, cynicism, and inefficacy.

\section{Meaning of Burnout}

The concept of burnout started as a "grassroots" description of prolonged occupational stress among human service workers, where former engaged employees gradually get overwhelmed of emotional exhaustion, loss of energy, and withdrawal from work.

\section{Definitions of Burnout}

According to Fruedenberger (1974) "Burnout is a state of chronic fatigue, depression and frustration brought about by devotion to a cause, way of life and relationship that not only fails to produce expected rewards but also ultimately leads to a lessened job involvement as well as lowered job accomplishment".

Christina Maslach and her colleagues (1982) "Conceptualized burnout as having three core components: emotional exhaustion, depersonalization and lack of personal accomplishment."

Pines and Aronson (1988) describe burnout as "a state of physical, emotional, and mental exhaustion caused by long term involvement in situations that are emotionally demanding". 
According to Brill (1984), "Burnout is an exceptionally mediated, job related dysphonic and dysfunctional state in an individual."

Schaufeli and Enzmann (1998) "Burnout is a persistent, negative, work- related state of mind in 'normal' individuals that is primarily characterized by exhaustion, which is accompanied by distress, a sense of reduced effectiveness, decreased effectiveness, decreased motivation, and a development of dysfunctional attitudes and behaviours at work.

\section{Historical background of Burnout}

The mid 1970's by two American researchers, Herbert Freudenberger and Christina Maslach, who independently of each other describe the phenomenon. Thus, the burnout concept was developed from field observations - not from theory. In a comprehensive review from 1998 Schaufeli and Enzmann conclude: "Burnout is not a new phenomenon - it has its root in the past. However, because of a unique constellation of several factors it was 'discovered' in the early 1970's as a particular type of prolonged occupational stress that seemed to occur most prominently among human services professionals".

\section{Areas of Work Life and Burnout}

Individuals experience burnout in the context of work. It differs in this respect from depression, a condition which encompasses many areas of a person's life. Individuals who are prone to depression are more likely to experience burnout than others are, but burnout also visits many who are not depressed. Certain job characteristics are known to contribute to burnout. These include high workload, time pressure, conflicting demands on the job, lack of adequate information to do the job well, lack of social support, especially from supervisors, and lack of feedback. Individuals who have little influence on decision-making tend to experience burnout more often than those who have more influence. Maslach and others have developed a useful theoretical model that considers how well or poorly a person fits their job with regard for six areas of work life-sometimes referred to as sometimes refer to as job-person fit. Each of these conditions is manifest along a continuum of possibilities. The more doubtful the fit, the more likely the person will experience burnout. A strong fit in these areas indicates a greater likelihood that the person is engaged in work.

A person's workload can be excessive or sustainable. If excessive, they may feel that they are overloaded. They may lack basic skills, sufficient time, emotional authenticity or other resources to complete assigned tasks effectively. An excess of workload compared with a shortage of resources, especially with insufficient opportunity for recovery, can deplete energy and lead to exhaustion.

They may have sufficient control of key processes, resources, or choices needed for success or a lack of control of one or more of these requirements. Control in this sense includes adequate authority to pursue tasks in an efficient manner. Lacking control to meet one's responsibilities may create a sense of loss of effectiveness. Financial, social or intrinsic rewards and recognitions may be appropriate or insufficient to match the work people do. Lack of appropriate reward or recognition can manifest itself in feelings of inefficacy.

The work community may be supportive or non-supportive. A supportive community reaffirms a person's membership in the organization or work unit through appropriate emotional exchanges with coworkers and supervisors. Supportive colleagues assist each other. They share values. Organizations in which there is chronic, unresolved conflict, isolation, frustration or hostility are non-supportive. Fairness, as a condition relating to respect and self-worth, is lacking in inequitable workload or pay situations, places where cheating for resources or attention is allowed, or where evaluations are not handled appropriately. Values relate to ethics, aspirations and the mission of the organization and are expressed in official policy and statements, but validated in actual practice.

\section{Dimensions of Burnout}

There are three dimensions of psychological burnout which are emotional exhaustion, depersonalization and lack of personal accomplishment (Leiter and Maslach, 1988).

* Emotional exhaustion is characterized by a lack of energy and a feeling that one's emotional resources are used up.

* Depersonalization or cynicism component typically occurs after emotional exhaustion which refers to a negative, callous or excessively detached response to various aspects of the job. It is described as the unconcerned and impersonal attitude which professionals develop while dealing with the clients.

* Diminished personal accomplishment or reduced efficacy represents the self- evaluation dimension of burnout, which refers to feelings of incompetence and a lack of achievement and productivity at work.

\section{Review of Related Literature}

Review of related literature is a scientific enquiry and analysis of related literature of given aspect helps in understanding the problem clearly, and to know what work has already been done in the area 
understudy and in allied areas. It helps in the improvement of ideas, specification of research procedures, clarity and understanding of thing to be done. The following studies on Burnout and occupational stress have been conducted all over the world and especially in the developing countries in the recent years. Some of the studies undertaken in different countries mentioned below:

Volpe (2014) in his article entitled "Burnout and stress in Library workplace" focus on job burnout and stress in the library profession, sources and symptoms \& organizational approaches and strategies responsible for burnout and stress among library employees. According to author the burnout \& stress inherent in the library work environment. The Librarian or Manger should aware of it \& should try to adjust their organizational environment to cope with stress and burnout.

Popoola, Olalude and Francis (2013) in their study entitled" Work values, achievement motivation \& techno stress as determinant of Job burnout among Library professionals in Automated Federal University in Nigeria" observed the sources of Burnout among the library professionals. The study examined that adoption of Information and Communication Technology by the university has made negative effect on the professionals \& which create the problem of techno stress. Through the study it has examined that there is positive relationship between techno stress and burnout while the contribution of work values and achievement motivation were negligible.

Somvir and Kaushik (2013) in their study "Occupational Stress among Library Professionals in Haryana" has investigated various aspect of occupational stress among library professional who are working in private Engineering and Management colleges in Haryana \& found that stress has influenced the performance of employees \& also made negative effect on work environment. It was also suggested that employees should be motivated with rewards, achievements $\&$ incentives to improve productivity which will reduce the stress among professionals.

Ajala (2011) studied on Work-related stress among Librarians and Information Professionals in a Nigerian University. In the study, the author found that there were inadequate working tools and resources, librarians don't have enough and adequate working tools in their own unit, which leads to work overload for them, the ergonomic problem affects their physical health; poor job incentives or rewards; interaction with other staff, i.e., dealing with conservative or bullying colleague and usage of harsh or abusive language. Home problems were also found a cause of stress. It was observed that librarians didn't have any fear about the job security in the Ibadan University library System. Males have more job dissatisfaction than the female staff; the older staff experiences more job satisfaction than the younger staff.

Routray and Satpathy (2007) described the types of stress in digital library environment and broadly divided them into: Technological, Physical, Mental and Situational. Technological stress was described as the stress due to the development and application of information technologies among the library and information professionals. Due to rapid change in computer hardware and software, obsolescence of existing hardware and software is a common phenomenon in almost all libraries. Thus there is the necessity to keep pace with the changing technologies which due to financial, time or technological constraints, it is difficult to do.

The study undertook by Togia (2005) mainly tries to measure the levels of stress among Greek Academic librarians and to assess its relation with certain background characteristics. The Maslach Burnout Inventory (MBI) was administered on a sample of 136 academic librarians across Greece. There were low levels of emotional exhaustion and depersonalization, and moderate levels of personal accomplishment were found in the study. Age, experience, and participation in decision making were found to be independent of the burnout experienced.

Sornam and Sudha (2003) attempted to study the influence of age, experience, marital status on ORS, and to find out the extent of association between selected socio demographic variables and occupational role stress among women library professionals working in Bharathidasan University in Tamil Nadu. As statistical tool the median, chi-square, Karl Pearson's and T-test were used. The results show that age, experience and marital status have significant association with ORS.

Haridasan and Sultan (2002) surveyed the library professionals of the Gorakhpur University to identify the role of different dimensions of stress experienced by the library staff working in different levels in the organization, and to study the personal factors causing the stress among library staff, etc. A sample of 62 members was taken to ascertain their stress experience. The findings show that the librarians are under stress as they are affected by role overload, role conflict, unreasonable group and political pressure, and under participation. The librarian also experience high levels of stress with the emotional exhaustion dimension.

Poole and Denny (2001) investigated the aspects of techno stress of librarians owing to the introduction of new technologies in the library field. An exclusive survey has been conducted at the Community College Library in Florida in USA to study the impact of technology on the library professionals. In this study it is examined how library professionals behave with technological change in the work environment in the Florida Community College Library and Learning Resource Centers. The result of the investigation indicated that the 
staff is reacting positively to the technological change and there was only a negligible stress related consequence of the change.

\section{Symptoms of Burnout}

There are a number of physical, psychological and behavioural changes which can be symptomatic of individual stress. These are:

* Physical symptoms are characterized by actual changes in physiological body functions such as physical exhaustion, fatigue, insomnia, headaches, gastrointestinal problems/ulcers, hypertension, high cholesterol, coronary disease and impaired speech.

* Psychological symptoms show themselves in the attitudes and feelings of the individual such as loss of flexibility, apathy, cynicism, emotional exhaustion, low morale, loss of patience, inability to cope with unwanted stress, feelings of anger, reduced self concept, dehumanizing, frustration, inability to make decisions, feeling of powerlessness, paranoia, feelings of failure, depression, alienation, increased worry, over confidence, stagnation, mood swings, general uneasiness etc.

* Behavioural symptoms reflect those actions or behaviours manifested as a result of burnout such as low job satisfaction, decreased communication, high job turnover, increased absenteeism, loss of enthusiasm for job, increased drug and alcohol use, increased marital and family conflict, accident proneness, forgetfulness, poor concentration, workaholics.

\section{THE CAUSES AND CONSEQUENCES OF JOB BURNOUT}

Evaluation of the current models used to explain burnout reveals that many studies probe the factors from a variety of angles, analyzing different aspects of the causes of burnout and its impact on organizations and employees. The causes of burnout are commonly categorized into two distinct kinds: individual and organization. Other studies have applied the conservation of resources theory to explore the causes of burnout on two particular aspects: job demands and individual resources. Job demands include role ambiguity, role conflict, pressure of events, work overload and work pressure. Individual resources include social support, recommencement contingencies, and job enhancement opportunities such as automation, policymaking and autonomy.

Overall, job burnout is correlated with many job negative reactions, i.e. consequences of burnout. Conducted studies show that burnout relates to job satisfaction and organizational commitment negatively and to intention to leave positively. Burnout tends to cause symptoms related to physiology, psychology, perception and behaviour. Pines claims that burnout leads to the de-motivation of employees, absence, impaired efficiency, reduced time on the job, high turnover intention rate, increased workload and poor work performance.

Matin, Kalali and Anvari also found that employees' job burnout leads to their organizational commitment and job satisfaction mitigation. On the other hand, job burnout leads into increase in employees' intention to leave. Burnout may reduce the level of work effectiveness, increase turnover intention rate and may also result in overspending on the training of new employees. Such factors are not simply a monetary cost they represent a considerable cost in terms of human labour and time.

\section{BURNOUT AMONG LIS PROFESSIONALS}

A search of the literature shows an abundance of research on job stress \& Burnout in various occupations has done. Most of the research articles are concerned with burnout in the helping professions which are in direct contact with recipients. But research into the field of librarianship has only begun in the last decade. The stress and burnout affect the effectiveness of the employees and the organization. With the development and application of information technologies, the library environment has changed from the traditional library to computerized library, then automated library and more recently digital library.

The Library professionals experience stress as they readjust their lives with the changing library environment, job rotation, job promotion, etc. While adjusting to such changing library environment, stress will either help or interrupt us depending on how we react to it. There is a pressure on the library professionals to adopt knowledge of new technologies along with traditional method of functions and services. But there is limited scope for training programs, higher studies, refresher courses, and this becomes a cause of stress among library professionals. The fear about job security is also a reason of stress among library professionals, because a lot of departments give appointment to the computer professionals. In Haryana state, most of the librarians are well qualified but they are directed for their work by institution's head or other senior staff, who are not aware of library functions or services. The situation becomes very awkward when librarians are compared with clerical staff and they have to work under-in-charge of library, who is related with other field \& who doesn't know the designation of a librarian and what are the responsibilities and duties of librarian. 
The library professionals are frustrated due to low salary, status, and responsibility for the missing books, and these factors are discouraging librarians to provide better library services. The librarians are also in stress due to low budget system. All these factors of stress further leads to prolonged stress which leads to Burnout.

\section{STRATEGIES FOR PREVENTING JOB BURNOUT}

* The library managers should encourage \& allow library professionals to attend the seminars, conference \& training workshop so that they can make aware themselves about new skills \& technologies.

* The library managers should encourage the library staff to take decisions about their surrounding which will create self-esteem among the personnel which will improve their service delivery \& will help in reducing job-burnout.

* The library management should give financial incentives \& all other entitlements to their staff which will motivate them for higher productivity.

* The library management should develop orientation program to improve the learning skill of staff which will prevent them from frustration.

* For preventing the occupational burnout, various stress management interventions have been shown to help improve employee health and wellbeing in the workplace and lower stress levels.

* The library management should make provision to provide training to employees to manage stress in the workplace, which will be proven as effective measure in prevention of burnout. The various studies on jobburnout show that social-cognitive processes such as commitment to work, self-efficacy, learned resourcefulness and hope may insulate individuals from experiencing occupational burnout.

* According to Maslach and Leiter burnout occurs due to disconnection between the organization and the individual with regard to the six areas of work life: workload, control, reward, community, fairness, and values. Resolving these discrepancies requires integrated action on the part of both the individual and the organization. The better connection on these discrepancies will encourage employees to revitalize their energy. A better connection on values means clear organizational values by which employees can feel committed.

* Job-rotation policy is another prevention measure by which employees may greatly appreciate a work rotation that gives them uninterrupted time to develop proposals or do other staff-level writing and this policy will help in reducing the job-burnout.

* Additional prevention methods to reduce the job-burnout are starting the day with a relaxing ritual, adopting healthy eating, exercising, and sleeping habits, setting boundaries, taking breaks from work, nourishing one's creative side, and learning how to manage stress.

\section{CONCLUSION}

Burnout and stress can happen in any type of work environment. In twenty-first century LIS professionals are facing constant challenges in their working environments. The LIS professionals in digital Library Environment, not only playing role inside their libraries, but also, exceed library's capacity in terms of documents, infrastructure facilities, finance, staff etc. In this context the LIS professionals have two choices, either to manage or control the situation that impact their work and produce stress, or to allow stress to manage them. It is not possible for the professionals to remove all causes of stress in the present library workplace but, the library managers can manage stress at some extend by adopting various measure like flexible organization policy, by creating supportive workplace atmosphere, by recognize the sign of stress and by giving financial incentives etc. which will help to reduce some of job-burnout consequences such as: poor morale, reduced performance and team conflict.

\section{REFERENCES}

[1] Ajala, E. B. (2011). Work related stress among librarians and information professionals in a Nigerian University. Library philosophy and practice. (Cited 17 November, 2016) Available from http://unlib.unl.edu/LPP/ajalla.html.

[2] Haridasan, S., \& Sultan, T. (2002). Occupational stress and burnout among the library staff of Gorakhpur University: A Survey. Journal of Library and Information Science, 27(1), 41-52.

[3] Poole, C. E., \& Denny, E. (2001). Technological change in workplace: A statewide survey of community college library and learning resources personnel. College and Research Libraries, 62 (6), 503-515. (Cited 17 November, 2016) Available from http://crl.acrl.org/content/62/6/503.full.pdf.

[4] Popoola, S. O., \& Olalude, F. O. (2013). Work values, achievement motivation and techno stress among library personnel in automated federal University in Nigeria. Library Philosophy \& Practice, 119. http://digital commons.unl.edu/libphilprac/919. 
[5] Routray, B. \& Satpathy, S. K. (2007). Stress management of library and information science professionals in digital environment. LIS E-Prints in Library and Information Science. (Cited 17 November, 2016) Available from http://www.eprints.rclis.org

[6] Somvir \& Kaushik, S. (2013). Occupational stress among library professionals in Haryana. International Journal of Knowledge Management \& Practices, 1 (1), 19-24.

[7] Sornam, S., \& Sudha, S. (2003). Occupational role stress on women librarians: A study. SRELS Journal of Information Management, 40 (2), 147-156. (Cited 17 November, 2016) Available from http://www.indianjournals.com/ijor.aspx

[8] Togia, A. (2005). Measurement of burnout and the influence of background characteristics in Greek academic librarians, Library Management, 26 (3), 130-138. . (Cited 17 November, 2016) Available from http://www.emeraldinsight.com/ journals.html.

[9] Volpe, S. (2014). Burnout and stress in the library workplace Ph. d thesis. Emporia State University.

\section{About Author}

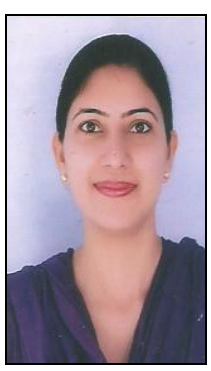

Rajinder Kaur Gill is presently working as a librarian in the Arya Kanya Mahavidyalya, Shahabad Markanda (Kurukshetra). She holds a post graduate in library \& information science and Pursing Ph.d from Kurukshetra University Kurukshetra. 